For the heat of combustion of urea Berthelot ${ }^{1}$ gives $15 \mathrm{r}, 600$ cal. and Stohmann ${ }^{2} 152,300$ cal. The deviation from its mean value $151,95^{\circ}$ is $350 \mathrm{cal}$. Using the values for the heats of formation of water and carbon dioxide given above, the heat of formation of urea from its elements is

$$
\Delta H_{298}={ }^{5} 5 \mathrm{I}, 950-2 \times 68,275-94,250=-78,850 \mathrm{cal} . \text {, }
$$

and the free energy of formation of urea from its elements is

$$
\Delta F_{298}=-78,850+298 \times 93.6=-50,960=3350 \mathrm{cal} \text {. }
$$

Lewis and Burrows ${ }^{3}$ found from measurements of equilibritum for the reaction

$$
2 \mathrm{NH}_{3}(\mathrm{~g})+\mathrm{CO}_{2}(\mathrm{~g})=\mathrm{CON}_{2} \mathrm{H}_{4}(\mathrm{~s})+\mathrm{H}_{2} \mathrm{O}(\mathrm{r}) ; \Delta F=-\mathrm{I} 77^{2} \mathrm{cal} .
$$

This gives for the free energy of formation of urea from its elements

$$
\Delta F_{298}=-48,992 \text { cal., }
$$

using for the free energy of formation of $\mathrm{NH}_{3}(\mathrm{~g}), \mathrm{CO}_{2}(\mathrm{~g})$ and $\mathrm{H}_{2} \mathrm{O}(\mathrm{l})$ the respective values $-4740 \mathrm{cal}$., $-94,360 \mathrm{cal}$. and $-56,620 \mathrm{cal}$.

\title{
Summary.
}

The specific heats of formic acid and urea have been measured over the temperature range $75^{\circ} \mathrm{K}$. to $298^{\circ} \mathrm{K}$., and their entropies and free energies have been calculated.

The values for the free energies agree within the experimental error with values calculated from equilibritum data. A check upon the validity of the third law of thermodynamics as applied to organic compounds has thus been obtained.

BERKELLE, CALIF.

[CONTRIBUTION FROM THE CHEMICAJ, LABORATORY OF THE UNIVERSITY OF California.]

\section{ENTROPY CHANGES AT LOW TEMPERATURES. II. ETHYL AND PROPYL ALCOHOLS AND THEIR EQUAL MOLAL MIXTURE.}

By G. E. Gibson, G. S. Parks and W. M. I ATmMer.

Received April 9, 1920.

In a previous paper ${ }^{4}$ Lewis and Gibson have discussed the applicability of the third law of thermodynamics to processes of solution. They conclude that the entropy of a solution should always exceed at the absolute zero the sum of the entropies of the pure crystalline constituents. They also suggest that the transition from a pure crystalline substance to the same substance in the form of glass may be accompanied by an increase in entropy. The object of the present investigation is to obtain additional experimental data suitable for testing these conclusions.

${ }^{1}$ Berthelot and Petit, Ann. chim. phys., [6] 20, 113 (1889).

2 Stohmann and Langbein, J. prakt. Chem., 44, 380 (I891).

3 Lewis and Burrows, TuIs Journal, 34, 993 (r9r2).

${ }^{4}$ Lewis and Gibson, ibid., 42, 1529 (1920). 
Ethyl alcohol and propyl alcohol were selected for this purpose because they both supercool readily to form glasses. Moreover, due to their close chemical relationship, they are very similar as regards internal pressure and dielectric constant, and for this reason a mixture of these 2 liquids may be assumed to conform to Raoult's law with fair exactness. ${ }^{1}$ Hence, for the process of mixing $1 / 2$ mol. of ethyl alcohol with $1 / 2$ mol. of propyl alcohol to produce one mol. of mixture, the entropy change is approximately $\Delta S_{298}=R \ln 2=+\mathrm{r} .37$ cal. per degree abs.

The question then is whether this positive entropy change persists down to the absolute zero in accordance with the argument of Lewis and Gibson, or whether it decreases with decrease of temperature and becomes zero in the limit. It was impossible for us to follow experimentally the behavior of the stibstances concerned down very near to the absolute zero, but it is exceedingly probable that between room temperature and the boiling point of liquid air any tendency toward change in the magnitude of the quantity $\Delta S$ for the process under consideration would become manifest. The specific heats of pure ethyl alcohol, pure propyl alcohol, and of the equimolal mixture (all in the liquid or vitreous condition) were, therefore, determined over the above range of temperature, and from these data the entropy changes in question have been calculated.

In the course of the experiments it was found that pure ethyl alcohol crystallized very readily. The heat of fusion and the specific heats of the crystalline form were, therefore, also determined. From these data the entropy change for the transition from the crystalline to the vitreous form has been calculated.

Applying the third law of thermodynamics to the same data, together with the heat of formation of ethyl alcohol, the free energy of formation at $25^{\circ} \mathrm{C}$. has been calculated.

\section{Experimental.}

The experimental procedure was essentially the same as that employed in the investigation of the specific heats of formic acid and urea, and has been discussed in the preceding paper.

The ethyl alcohol and propyl alcohol used were pure commercial products. They gave no test for aldehydes. The ethyl alcohol as taken from the bottle had a specific gravity corresponding to $99.6 \%$ and was used in determining the heat of fusion, the specific heats of the glass, and the specific heats of the crystalline form between $120^{\circ}$ and $145^{\circ} \mathrm{K}$. A sample of this alcohol was distilled over metallic sodium and used for the determination of the specific heats of the crystalline form from $88^{\circ}$ to II $5^{\circ} \mathrm{K}$, and of the liquid at and above $195^{\circ} \mathrm{K}$. The propyl alcohol had a mean

1 As a matter of fact, Bose in his measurements finds that $\Delta H$ for the above process is $-5.8 \mathrm{cal}$. at $273.4^{\circ} \mathrm{K}$. and $-6.9 \mathrm{cal}$. at $294.6^{\circ} \mathrm{K}$. This small heat of mixing would indicate that no great error is made iri the above assumption that the mixture couforms to Raoult's law and that $\Delta H=0$. Bose, Göttingen Ges. Nachr. 1906, 333. 
boiling temperature of $97^{\circ} \mathrm{C}$. with a boiling range of approximately $I^{\circ}$. This liquid was fractionally distilled over anhydrous potassium carbonate, and the middle portion, about $1 / 2$ of the total, was used for these determinations.

It is believed that the error in most of the results which follow does not exceed $\mathrm{I} \%$, or at most $1.5 \%$. The region where the values are least concordant is in the range from $100^{\circ}$ to $125^{\circ} \mathrm{K}$. in the cases of the propyl alcohol and mixed alcohol glasses. At these temperatures it is rather hard to maintain the surroundings of the calorimeter at reasonably con-. stant temperature over the required period of time. Moreover, the glasses begin to soften and become jelly-like, and their thermal conductivity is probably lowest at this stage. The error in the values obtained in this region may be as high as 4 or $5 \%$ in some cases. For this reason, the runs which from the nature of the determination are regarded as least reliable, are marked with an $\mathrm{X}$.

Specific Heats.

\begin{tabular}{|c|c|c|}
\hline $\begin{array}{l}\text { Temperature. } \\
\text { I. }\end{array}$ & $C_{p}$ per g. & $C_{p}$ per $\mathrm{g}_{\text {. atom }}$ \\
\hline 85.9 & 0.266 & I. $36 \mathrm{I}$ \\
\hline 87.0 & 0.268 & $x .37 \mathrm{I}$ \\
\hline $9 \mathrm{r} .0$ & 0.283 & I. .448 \\
\hline 92.0 & 0.289 & $x .479$ \\
\hline 92.4 & 0.296 & I.5I5 \\
\hline 94.6 & $0.3 \times 3$ & I. 602 \\
\hline 96.3 & 0.370 & I. 893 \\
\hline
\end{tabular}

TABLE II.-ETHY, ATCOHOL: LigUID.

$\begin{array}{cccccc}\text { Temperature. } & C_{p \text { per } g .} & C_{p} \text { per atom. } & \text { T. }{ }^{\circ} \mathrm{K} . & C_{p} \text { per g. } & C_{p} \text { per g. atom. } \\ 196.2 & 0.456 & 2.332 & 201.4 & 0.459 & 2.349 \\ 196.3 & 0.46 \mathrm{I} & 2.359 & 205.4 & 0.462 & 2.363 \\ 198.2 & 0.463 & 2.369 & 262.7 & 0.524 & 2.680 \\ 199.0 & 0.455 & 2.329 & 267.2 & 0.527 & 2.696 \\ 199.2 & 0.456 & 2.332 & 267.9 & 0.527 & 2.696 \\ \ldots & \ldots & \ldots & 271.4 & 0.531 & 2.717\end{array}$

Table III.-Etrhyl Alcohol, Propyl Alconol, Eoumolal. Mixuture: Glass and

\begin{tabular}{|c|c|c|c|}
\hline \multirow{2}{*}{$\begin{array}{l}\text { Temperature. } \\
\underset{\mathbf{K} .}{ }\end{array}$} & \multicolumn{2}{|c|}{ Iigurd. } & \multirow[b]{2}{*}{$C_{p}$ per $\mathrm{g}}$. \\
\hline & $C_{p}$ per g. & $\mathrm{T} .{ }^{\circ} \mathrm{K}$. & \\
\hline 78.5 & 0.234 & $\operatorname{Ix} 7.3$ & 0.472 \\
\hline 85.2 & 0.242 & 195.9 & 0.448 \\
\hline 86.4 & 0.249 & I96.8 & 0.448 \\
\hline 86.9 & 0.250 & 197.0 & 0.452 \\
\hline 88.4 & 0.256 & 199.4 & 0.447 \\
\hline 91.8 & 0.264 & $200 \cdot 3$ & 0.445 \\
\hline 92.2 & 0.275 & 200.5 & 0.454 \\
\hline 92.7 & 0.278 & $26 x .7$ & $0.5 x_{3}$ \\
\hline 94.2 & 0.301 & 265.8 & $0.52 \mathrm{x}$ \\
\hline 97.9 & 0.400 & 269.2 & 0.525 \\
\hline 98.0 & 0.393 & 269.4 & 0.524 \\
\hline 103.7 & $0.468 \mathrm{x}$ & $273 . \mathrm{X}$ & 0.524 \\
\hline 103.8 & 0.482 & 273.2 & 0.528 \\
\hline$x \times 0.8$ & 0.476 & $\cdots$ & $\cdots$ \\
\hline
\end{tabular}


TABle IV,-Propyl Alcohol: Glass and Liguid.

\begin{tabular}{|c|c|c|c|c|c|}
\hline $\begin{array}{c}\text { Cemperature. } \\
{ }_{\mathrm{K}} \mathrm{K} \text {. }\end{array}$ & $c_{p}$ per $g$. & $C_{p}$ per atom. & s. ${ }^{\circ} \mathbf{K}$. & $C_{p}$ per g. & $C_{p}$ per g. atom. \\
\hline 77.0 & 0.223 & I. 155 & 596.8 & 0.440 & 2.202 \\
\hline 82.9 & 0.234 & I. . I $7 \mathrm{I}$ & 197.7 & $0.44^{2}$ & $2.2 \mathrm{II}$ \\
\hline $87 \cdot I$ & 0.244 & $\mathrm{I} .22 \mathrm{I}$ & 199.0 & 0.446 & 2.232 \\
\hline 87.2 & 0.246 & 1.231 & 199.3 & 0.447 & 2.237 \\
\hline 88.4 & 0.247 & 1.236 & .999 .6 & 0.445 & 2.228 \\
\hline 88.7 & 0.248 & 1. 239 & 200.8 & 0.446 & 2.232 \\
\hline 89.5 & 0.247 & I. 2.36 & 206.0 & 0.451 & 2.258 \\
\hline 89.7 & $0.25 \mathrm{I}$ & $x .256$ & 250.7 & 0.447 & 2.237 \\
\hline 92.8 & 0.269 & I. 34.6 & $2 \pi 4 \cdot 4$ & 0.453 & 2.267 \\
\hline 93.4 & 0.273 & I. 366 & 219.0 & $0.46 \mathrm{x}$ & 2.307 \\
\hline 95.0 & 0.287 & 1.436 & 222.8 & 0.456 & $2.28 \mathrm{I}$ \\
\hline $96: 0$ & 0.293 & 1.466 & 227.0 & $0.45^{8}$ & 2.293 \\
\hline 98.2 & 0.346 & $x .731$ & $23 I . I$ & 0.459 & 2.298 \\
\hline 98.3 & 0.353 & 1.767 & 235.2 & 0.466 & 2.333 \\
\hline 100.2 & 0.451 & 2.058 & 235.9 & 0.469 & $2 \cdot 34^{8}$ \\
\hline 102.7 & $0.428 \mathrm{x}$ & $2.14 \mathrm{IX}$ & 239.0 & 0.470 & 2.353 \\
\hline 103.2 & 0.458 & 2.292 & $240 . I$ & 0.476 & $2 \cdot 383$ \\
\hline 104.8 & $0.437 x$ & $2.188 \mathrm{x}$ & 243.8 & 0.476 & 2.382 \\
\hline 108.9 & 0.450 & $2.25 \mathrm{I}$ & 247.8 & 0.487 & 2.439 \\
\hline $\operatorname{IOg} .9$ & 0.464 & $2.32 x$ & 252.1 & 0.489 & $2 \cdot 447$ \\
\hline$x \times 5.0$ & 0.453 & 2.268 & 256.2 & 0.492 & 2.463 \\
\hline$x 15.8$ & $0.48 I X$ & 2.408 & 258.8 & 0.502 & $2.5 \mathrm{I} 2$ \\
\hline 121.7 & 0.437 & 2.188 & 261.5 & 0.504 & 2.522 \\
\hline$x 23.8$ & $0.455 x$ & $2.278 x$ & $264 \cdot 5$ & 0.511 & 2.557 \\
\hline$\times 65.7$ & 0.429 & 2.147 & 267.5 & 0.553 & 2.568 \\
\hline 177.0 & $0.43 \mathrm{I}$ & 2.56 & 274.6 & 0.522 & $2.6 \times 2$ \\
\hline 187.4 & 0.440 & $2.20 \mathrm{I}$ & $\ldots$ & $\ldots$ & $\cdots$ \\
\hline
\end{tabular}

\begin{tabular}{|c|c|c|c|c|c|}
\hline $\begin{array}{l}\text { enperature. } \\
\text { o. }\end{array}$ & $C_{p}$ per g. & $C_{p}$ per atom. & T. ${ }^{\circ} \mathbf{K}$. & $C_{p}$ per g. & $C_{p}$ per g. atom \\
\hline 88.0 & 0.240 & 1.228 & 113.8 & 0.284 & $x .455$ \\
\hline 88.7 & 0.243 & 1.244 & \pm 21.8 & 0.299 & $\mathrm{I} .530$ \\
\hline 89.8 & 0.243 & บ. 245 & 126.2 & 0.305 & 1.560 \\
\hline $92 \cdot 3$ & 0.246 & I. 260 & 129.5 & 0.308 & I. .577 \\
\hline 94.9 & 0.250 & 1.277 & $3 I .4$ & $0.3 \pm 5$ & I. 613 \\
\hline 100.9 & 0.257 & 1.317 & 136.0 & 0.329 & I. 682 \\
\hline ז06.3 & 0.275 & I. $40^{\circ}$ & 136.6 & 0.329 & I. 684 \\
\hline 106.7 & 0.270 & 1.384 & $14 \pi .4$ & 0.366 & 1. .872 \\
\hline 112.6 & 0.282 & $x .44 I$ & $\ldots$ & $\ldots$ & $\ldots$ \\
\hline
\end{tabular}

Heat of Fusion of Ethyl Alcohol at the Melting Point $55^{6.2^{\circ} \mathrm{K}}$.

First determination...... 24.4 cal. per g.

Siecond determination.... 23.7 cal. per g.

Mean result......... 24. o cal. per g. or I23 cal. per g. atom.

\section{Discussion of the Entropy of the Mixture.}

At the temperature of solid carbon dioxide or above, the specific heats of the substances under consideration are varying but slightly, and over intervals of $10^{\circ}$ or $15^{\circ}$ conform closely to a straight line relationship. Hence, if we average the temperatures for a number of neighboring runs and also 
the corresponding specific heats, we obtain mean values in which the accidental errors have been cancelled or minimized to a large extent. Thus the runs between $\mathrm{r} 95^{\circ}$ and $202^{\circ} \mathrm{K}$. were averaged for each of the alcohols with the following result.

\begin{tabular}{|c|c|c|}
\hline & Temperature. & $C_{p}$ per $\mathrm{g}$. \\
\hline 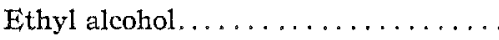 & . $\quad 198.4$ & $3 \mathrm{cal}$. \\
\hline Pro & 198.9 & 0.4443 cal. \\
\hline xture. & . $\quad 198.3$ & $0.4492 \mathrm{cal}$ \\
\hline
\end{tabular}

The mean temperatures thus obtained are not identical, but, since the curve for propyl alcohol shows that $\mathrm{d} C_{p} / \mathrm{d} T$ per $\mathrm{g}$. is 0.0005 at these temperatures, we may compute $\mathrm{C}_{p}$ for propyl alcohol at $198.3^{\circ}$, which is the temperature of the mean result for the mixture. Undoubtedly ethyl alcohol has practically the same temperature coefficient, so we can correct in its case in similar fashion.

In this tnanner Table VI was constructed by averaging the runs in the intervals $195^{-202^{\circ}} \mathrm{K}$. and $26 \mathrm{r}-275^{\circ} \mathrm{K}$. Since the value for $\mathrm{C}_{p}$ in the case of the glasses at liquid air temperatures is changing with extreme rapidity, the specific heats in this region were plotted against temperature for each substance, a smooth curve was drawn, and the values for $C_{y}$ at $86^{\circ}$ and at $90^{\circ}$ were then obtained from this curve. The product of $C_{p}$ per $\mathrm{g}$. and the molecular weight gives the molecular heat capacity which is the quantity that primarily interests us in the present discussion.

$\begin{array}{ccccc}\text { Temperature. } & \text { TABLE VI-MOLECULAR HEAT CAPACITIES. } & \\ 0 \mathrm{~K} . & \mathrm{C}_{2} \mathrm{H}_{5} \mathrm{OH} . & \mathrm{C}_{3} \mathrm{H}_{7} \mathrm{OH} . & \text { Equimolal mixture. } & \text { Mean. } \\ 268.7 & 24.39 & 30.96 & 27.72 & 27.67 \\ 198.3 & 21.10 & 26.67 & 23.83 & 23.89 \\ 90.0 & 12.80 & 15.17 & 13.90 & 13.98 \\ 86.0 & 12.15 & 14.47 & 13.21 & 13.31\end{array}$

The second, third and fourth columns of the above table contain the molecular heat capacities of ethyl alcohol, propyl alcohol, and of the equimolal mixture, respectively. The values in the fifth column are the mean of those in the second and third. From the data it appears that the molecular heat capacity of the mixture is approximately the mean of the values for the pure alcohols, a result which Bose found to be also true at $276.9^{\circ}$ and at $296.3^{\circ} \mathrm{K}$. for these same substances. This fact indicates that the entropy change involved in the formation of the equimolal mixture persists without appreciable diminution down to $86^{\circ} \mathrm{K}$. Furthermore, there is nothing which indicates that the quantity $\Delta S$ would decrease at any point below this temperature, and hence it seems reasonable to conclude that the entropy of the equimolal mixtute is greater than zero at the absolute zero in agreement with the argument of Lewis and Gibson.

${ }^{1}$ Bose, Göttingen Ges. Nachr. 1906, 298. 


\section{The Entropy Difference between the Two Forms of Ethyl Alcohol.}

When a sample of propyl alcohol or of the equimolal mixture was cooled in liquid air, it became more and more viscous. At $125^{\circ} \mathrm{K}$. the substance reached a jelly-like consistency; on further decrease in temperature the liquid underwent a noticeable contraction and solidified to a hard, transparent glass. Pure ethyl alcohol, if rapidly cooled, exhibited the same behavior but with slow cooling crystallized completely.

The specific heats of propyl alcohol and of the mixture show some remarkable changes in the course of this temperature decrease. In the neighborhood of $130^{\circ} \mathrm{K}$. they begin to increase as the temperature is lowered, reaching a maximum at $105^{-110^{\circ}} \mathrm{K} .^{1}$ With a further decrease the solid glass is formed and the heat capacity changes very greatly, falling off in the interval $90-100^{\circ} \mathrm{K}$. to about $1 / 2$ of its value in the liquid state. In the case of the ethyl alcohol glass the data are not so complete, owing to the greater difficulty in preventing crystallization. Sufficient determinations, however, have been made to indicate that super-cooled. ethyl alcohol is analogous to super-cooled propyl alcohol, and hence we may draw the 2 specific heat curves parallel for these substances.

For crystalline ethyl alcohol $C_{p}$ was plotted against $\log T$ between $78^{\circ}$ and $156.5^{\circ} \mathrm{K}$, the melting point of the substance. In like manner the

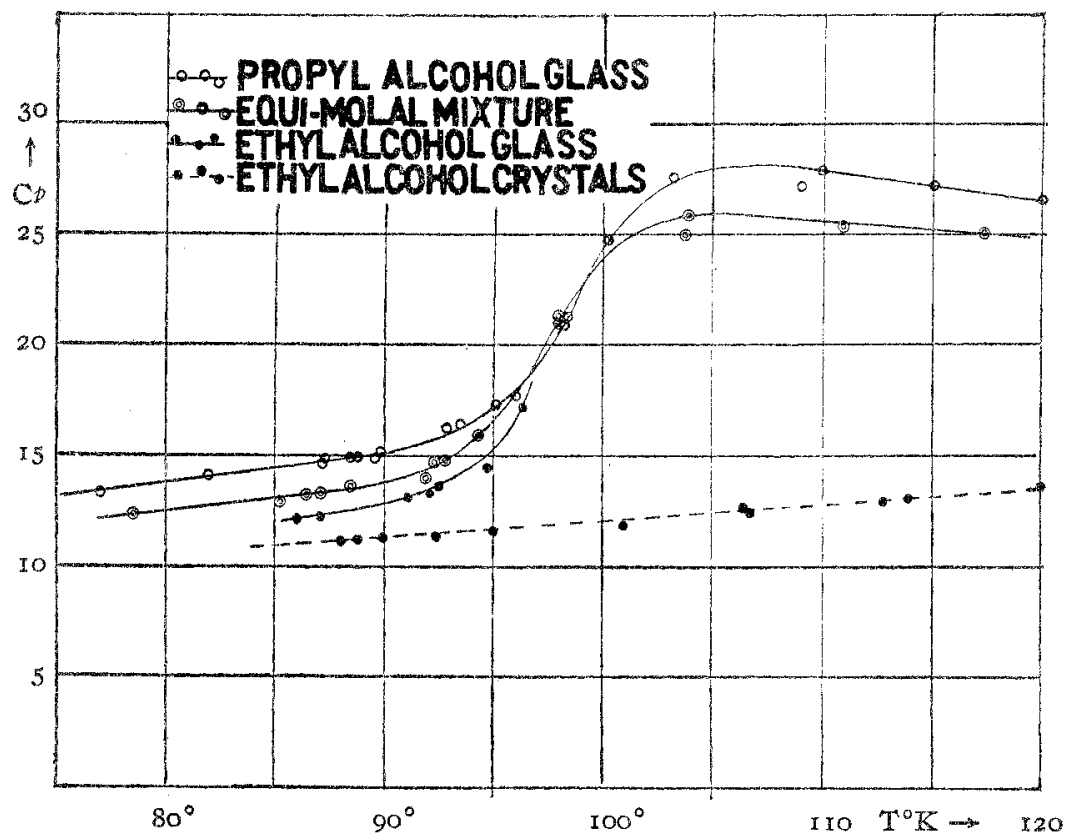

1 It is thought that the high specific heats in this region may be due to a great increase in the amount of association within the super-cooled liquid; this is the ustral explanation for the anomalous behavior of water from $-5^{\circ}$ to $15^{\circ} \mathrm{C}$. 
curve for super-cooled ethyl alcohol was drawn over the same temperature range. The area between the 2 curves is then a measure of the difference between the increase of entropy of the glass and the increase of entropy of the crystalline form over the interval $78^{-1} 5^{6.5^{\circ}}$. This difference, obtained by graphical integration, amounts to $0.5^{\circ} \mathrm{cal}$. per degree per mean g. atom. At $78^{\circ} \mathrm{K} . C_{p}$ for the glass is approximately $12 \%$ greater than $C_{p}$ for the crystals, but at lower temperatures the 2 curves probably approach much closer to one another. Thus White's ${ }^{1}$ data for the silicates and Koref' ${ }^{2}$ for crystalline and amorphous betol show that at a considerable distance below the melting point the specific heat of the glass exceeds: that of the solid by only $\mathrm{I}$ or $2 \%$. However, for the present argument: we will assume that below $78^{\circ}$ the difference of $12 \%$ in the specific heats; of the two forms is maintained practically down to $0^{\circ} \mathrm{K}$. For crystalline: alcohol the entropy increase, calculated by means of the " $n$ formula" of Lewis and Gibson, is $I .32$ for the interval $0-78^{\circ} \mathrm{K}$. Hence, on the assumption of $12 \%$ difference in $C_{p}$, the entropy of the glass exceeds that of the crystalline form by $\mathrm{r} .32 \times 0.12=0.16 \mathrm{cal}$. per degree. If then we assume that the entropy for both forms is zero at the absolute zero, the entropy change for the process, liquid alcohol $\rightarrow$ crystalline alcohol, becomes $\Delta S_{155,5}=-(0.50+0.16)=-0.66 \mathrm{cal}$. per degree per $\mathrm{g}$. atom, while when calculated from the heat of fusion

$$
\Delta S_{156.5}=\frac{223}{156.5}=-0.78 \mathrm{cal} . / \mathrm{deg} .
$$

This discrepancy of 0.12 entropy units per mean g. atom (or 20 calories at $55.5^{\circ}$ ) could be accounted for if we assume simultaneously an error of $21 \% \%$ in the determination of the heat of fusion and a $9 \%$ error in the: specific heats of the glass over the temperature interval $95^{-156.5^{\circ}}$. While errors of this magnitude seem improbable, the assumptions made: and the absence of data at and just above the temperature of liquid hydrogen hardly justify us in concluding that the entropy of the glass is; really different from that of the crystalline form at the absolute zero.

\section{Calculation of the Free Energy of Ethyl Alcohol.}

Assuming the entropy at the absolute zero to be zero, the entropy at $298^{\circ} \mathrm{K}$. is given by the equation

$$
S_{298}=\int_{0}^{298} \frac{\mathrm{d} Q}{T}
$$

Then for pure ethyl alcohol we may write

$$
S_{298}=\int_{0}^{156.5} \frac{C_{p} \text { (solid) } \mathrm{d} T}{T}+\frac{\Delta H \text { (fusion) }}{156.5}+\int_{156.5}^{298} \frac{C_{p} \text { (liquid) } \mathrm{d} T}{T} .
$$

The values of the integrals may be obtained by plotting $C_{n}$ as ordinates

"White, Am. J. Sci., 47, I (1919).

"Nernst. Knot and Lindeman, Sitzb. Akad., Ioro, 247. 
against $\ln T$ as abscissas, the entropy then being the area under the curve. As in the present case, the curve is not known below $85^{\circ} \mathrm{K}$., some extrapolation formula becomes necessary. Lewis and Gibson ${ }^{1}$ suggest for all solids

$$
C v=f\left(T^{n} / \theta^{n}\right)
$$

where $T$ is the absolute temperature, $\theta$ and $n$ are characteristic constants for each substance, and $f$ is the same function for different substances. For elements crystallizing in the regular system $n$ is unity; for all other substances it is less than unity.

Applying the methods of Lewis and Gibson, we obtain for crystalline ethyl alcohol $n=0.315, \theta=4.73^{\circ}, \log { }_{15} 6.5 / \theta^{\prime}=-0.15$ and $\mathrm{S}_{16.5}=2.35$ per g. atom. The entropy of fusion is equal to $123 / 156.2$ or 0.79 per $g$. atom. The increase of entropy per atom for liquid ethyl alcohol between $156.2^{\circ}$ and $298^{\circ}$ was obtained graphically by plotting $C_{p}$ against the corresponding logarithm of the temperature. The values of $C_{p}$ found experimentally at ice and at carbon dioxide temperatures were used and between these points the curve was drawn parallel to the curve for propyl alcohol. The values of Bose were used between $275^{\circ}$ and $298^{\circ} \mathrm{K}$. The integral $\int_{156.2}^{298} C_{b} \mathrm{~d} \ln T$ was found to be $\tau .59$ per $\mathrm{g}$. atom. Hence for ethyl alcohol

$$
S_{298}=9(2.35+0.79+1.59)=42.6 \text { per mol. }
$$

For the heat of combustion of liquid ethyl alcohol, Landolt-Börnstein give 3 values: 326,100 cal. (Berthelot), 326,700 (Atwater and Snell), and 326,900 (Atwater and Snell). We shall take the mean value 326,600 cal. For the heat content of the products of combustion we shall use the values

$$
\mathrm{H}_{2} \mathrm{O}=-68,275 \mathrm{call}^{2} \text { and } \mathrm{CO}_{2}=-94,250 \mathrm{cal}^{3}
$$

Then for the reaction

$$
\begin{aligned}
& 3 \mathrm{H}_{2}+0.5 \mathrm{O}_{2}+{ }_{2} \mathrm{C}=\mathrm{C}_{2} \mathrm{H}_{5} \mathrm{OH} \\
& \Delta \mathrm{H}_{298}=-66,700 \text { cal. }
\end{aligned}
$$

For the entropies of hydrogen, oxygen and carbon, Lewis and Gibson have calculated 15.9, 24.I and 1.3, respectively. With these values,

$$
\Delta S_{298}=42.6-95.4-24 . I-2.6=-79.5 \text {. }
$$

Hence, using the relationship $\Delta F=\Delta H-{ }^{*} T \Delta S$, we obtain

$$
\Delta F_{298}=-66,700+(298)(79.5)=-43,000 \text { cal. }
$$

\section{Summary.}

Specific heat data for ethyl alcohol, propyl alcohol, and for an equimolal mixture, all in the liquid or supercooled condition, have been obtained

2 Lewis and Gibson, loc. cit.

${ }^{2}$ Lewis and Randall, This JournaL, 36, 1069 (1914).

3 Lewis and Randall, ibid., 37, 488 (I915) 
over a wide range of temperature. The specific heat and heat of fusion of crystalline ethyl alcohol have also been measured.

From an examination of the data, it appears probable that the entropy of the equimolal mixture is not zero at the absolute zero.

With the assumption of the applicability of the third law to the process $\mathrm{C}_{2} \mathrm{H}_{5} \mathrm{OH}$ (super-cooled) $\rightarrow \mathrm{C}_{2} \mathrm{H}_{5} \mathrm{OH}$ (crystalline), $\Delta S_{155 \cdot 2}$ has been calcu lated in two ways. The difference (per gram atom) between the results obtained is 0.12 cal. per degree, or 20 calories at $156.2^{\circ} \mathrm{K}$.

By means of the third law of thermodynamics the free energy of pure ethyl alcohol has been calculated. $F_{298}{ }^{\circ}=-43,000$ cal.

BERKELEY, CALLF.

[CONTRIBUTION From the WOLCOTT Gibbs Memortal, Laboratory, HaRvard UNIVERSTTY.]

\section{THE MELTING POINTS AND THERMOELECTRIC BEHAVIOR OF LEAD ISOTOPES.}

\section{By Theionorfy W. Richards and Norris F. Hall.} Received April 17, 1920.

Among the properties of the isotopes of lead, the melting points stand out as of especial interest. Since the molecular volumes of these substances are essentially equal, ${ }^{1}$ the question as to whether or not the melting points are likewise equal, compels attention.

Thermocouples were used for this measurement, not only because they could be used with small amounts of material but also because they are essentially suited to "differential" estimation. W. P. White's papers" on this topic afforded many useful suggestions.

The thermo elements employed were 4 in number, 3 single elements and one of 4 junctions. The diffeulty with work at high temperatures is the breaking down or the increasing conductivity of most insulating materials even below the melting point of lead. Through the kindness of Professor Harvey N. Davis and Dr. F. Wheeler Loomis, asbestosinsulated copper and nickel wire were available for the construction of the elements. This combination has thermoelectric advantages. The thermoclectric effect (about 23 tuicrovolts per degree at $327^{\circ}$ ) is much higher than that of noble-metal elements, although not so high as copperconstantan; moreover, both sorts of wire are generally very free from the inhomogeneity often met with in alloys, and both metals are sufficiently resistant to oxidation under ordinary conditions.

The use of copper here as well as for connections to the rest of the measuring apparatus diminishes the danger of parasitic effects to a minimum.

1. See T. W. Richards and Charles Wadsworth, 3Td, THIS JournaL, 38, 22x, 1658 (9976).

${ }^{2}$ W. P. White, ibid., 36, I856-1885, $2011-2020$ (I914). 